\title{
Co-Doped mesoporous titania photocatalysts prepared from a peroxo-titanium complex solution
}

Ibrahim El Saliby ${ }^{\mathrm{a}}$, Laszlo Erdei ${ }^{\mathrm{b}}$, Andrew McDonagh ${ }^{\mathrm{c}}$, Jong-Beom Kim ${ }^{\mathrm{d}, \mathrm{e}}$, Jong-Ho Kim,e and Ho Kyong Shon ${ }^{\mathrm{a} *}$

${ }^{a}$ Faculty of Engineering and Information Technology, University of Technology Sydney, NSW 2007, Australia

b Faculty of Engineering and Surveying, University of Southern Queensland, QLD 4350, Toowoomba, Australia

${ }^{c}$ Faculty of Science, University of Technology Sydney, NSW 2007, Australia

d The Research Institute for Catalysis, Chonnam National University, Gwangju 500-757, South Korea

e Photo \& Environmental Technology Co. Ltd., Gwangju 500-460, South Korea

*Corresponding author email: hokyong.shon-1@uts.edu.au, Phone: +61 29514 2629, fax: +61295142633

\section{Abstract}

In this study, nitrogen doped and nitrogen/silver co-doped $\mathrm{TiO}_{2}$ photocatalsysts were fabricated using a sol-gel method at room temperature. The obtained gels were neutralised, washed with pure water, and calcined at $400{ }^{\circ} \mathrm{C}$ for 4 hours. The photocatalysts were characterised by scanning and transmission electron microscopy, X-ray diffraction, diffuse reflectance spectroscopy, X-ray photoelectron spectroscopy, and BET specific surface area. 
The results showed that spherical particles with anatase structure were produced after annealing at $400{ }^{\circ} \mathrm{C} . \mathrm{N}$ 1s $(400 \mathrm{eV})$ and $\mathrm{Ag} 3 \mathrm{~d}(367.3 \mathrm{eV})$ states indicated that nitrogen doping and silver co-doping were in the form of NO bonds and AgO, respectively. The photocatalytic activity of photocatalysts was investigated using a batch reactor system exposed to artificial solar irradiation. Both nitrogen and silver/nitrogen co-doped materials were effective in the photocatalytic degradation of hexamethyl pararosaniline chloride.

Keywords: $\mathrm{TiO}_{2}$, solar light, photocatalysis, co-doping, crystal violet. 


\section{Introduction}

Recent advances in material synthesis have combined the development of interesting microstructures and nanoassemblies with environmental applications such as water purification. Investigations into photocatalytic reactions with doped $\mathrm{TiO}_{2}$ have shown enhanced reactivity under visible light irradiation compared with undoped $\mathrm{TiO}_{2}$ [1-3]. Sato et al. [1] were the first to describe the synthesis of nitrogen-doped $\mathrm{TiO}_{2}$ obtained by calcination of titanium hydroxide. The authors confirmed that nitrogen was acquired from $\mathrm{NH}_{4} \mathrm{OH}$, which was used in the hydrolysis of $\mathrm{TiCl}_{4}$ to prepare titanium hydroxide. Asashi et al. [2] reported that substitutional doping using several non-metal elements promotes the visible light reactivity of $\mathrm{TiO}_{2}$. Moreover, they stated that nitrogen doping was the most effective because a band-gap narrowing was attained by mixing the $p$ states of $\mathrm{N}$ with $\mathrm{O} 2 p$ states. Consequently, many research groups [4-12] have reported theoretical and experimental studies on promising methods to produce visible-light sensitive $\mathrm{TiO}_{2}$ photocatalysts. Burda et al. [4] noticed that the direct amination of $\mathrm{TiO}_{2}$ changed the original whitish colour to yellow. The incorporation of $\mathrm{N}$ into the $\mathrm{TiO}_{2}$ cluster has been achieved by a number of methods. Ammonolysis, wet chemical route and modified peroxide sol-gel method have been reported by Michalow et al. [7], Bianchi et al. [13] and Jagadale et al. [6], respectively. Generally, the use of aqueous ammonia for the preparation of peroxotitanate complexes and $\mathrm{TiO}_{2}$ nanomaterials is used [6,14-17]. Nevertheless, previous work mainly focused on changes in morphology and crystal phase of $\mathrm{TiO}_{2}$ rather than on $\mathrm{N}$ doping.

Metal co-dopants such as $\mathrm{W}, \mathrm{V}$ and Ag can further enhance the photocatalytic reactivity of $\mathrm{TiO}_{2}$ nanopowders [18-20]. The preparation of nitrogen and silver co-doped nanomaterials using a peroxide method was achieved by soaking $\mathrm{TiO}_{2}$ in a solution of $\mathrm{H}_{2} \mathrm{O}_{2}$ and $\mathrm{NH}_{4} \mathrm{OH}$ [20]. The obtained nanopowders showed reactivity under visible light for the photodegradation of methylene blue. Multidimensional nanoassemblies and microstructures 
have also been examined including high-performance $\mathrm{Ag} / \mathrm{TiO}_{2}$ nanofiber membranes [23], nitrogen-doped flower-like $\mathrm{ZnO}$ materials [24] and the self-etching reconstruction of mesoporous $\mathrm{F}_{-} \mathrm{TiO}_{2}$ hollow microspheres [25].

Many dye wastewaters represent threat to the environment, by colouring natural water and destabilising the equilibrium of ecosystems. Several ways could be used to treat dye wastewaters, for instance, heterogeneous photocatalysis is an effective technology for decomposing cytotoxic and carcinogenic dyes into harmless inorganic compounds. Crystal violet (CV) has been previously used as a model organic pollutant to test the efficiency of photocatalytic systems [21-22]. The photodegradation pathways of CV were reported [22] and occur in several steps: at the beginning, the generation of many $\mathrm{N}$-demethylated intermediates is predominant, then, pararosaniline is formed as a final dye, at the end, several mineralisation reactions of organic by-products (formic acid, oxalic and acetic acids) take place.

Here, we report a novel peroxide method for the preparation of mesoporous photocatalysts doped with silver and nitrogen. The incorporation of dopants was achieved by the dissolution and precipitation of $\mathrm{TiO}_{2}$ nanopowder (Evonik P25) at room temperature. The doped products were characterised for morphological and chemical changes and their photocatalytic activity was tested for the photodegradation of crystal violet under solar light.

\section{Experimental}

\subsection{Materials}

Aeroxide ${ }^{\circledR} \mathrm{TiO}_{2}$ (Degussa Evonik P25), which is comprised of a mixture of anatase, rutile and amorphous structures, with a mean surface area (BET) of $50 \mathrm{~m}^{2} / \mathrm{g}$, was used as received. Ammonium hydroxide (25\% w/w) was purchased from Fluka (Sigma-Aldrich, Germany); silver nitrate (99.5\%) was obtained from Fluka (Sigma-Aldrich, UK), and hydrogen peroxide 
(50\%, ACR laboratory reagent) from Australian Scientific. Nitric acid (69.5\%, reagent grade, Scharlau chemie S.A) and hydrochloric acid (37\%, reagent grade, Scharlau chemie S.A) were used for pH adjustment. CV (88\% purity) was acquired from Chem-supply Pty Ltd (South Australia, Australia). Ultrapure (Milli-Q) water was used to prepare solutions.

\subsection{Synthesis of photocatalysts}

Nitrogen-doped $\mathrm{TiO}_{2}$ nanoparticles were prepared by dissolving $1 \mathrm{~g}$ of $\mathrm{TiO}_{2}$ powder in a mixture of $10 \mathrm{ml}$ of ammonium hydroxide and $20 \mathrm{ml}$ of hydrogen peroxide in a Teflon cell at room temperature (Figure 1). The mixture was neutralised with $1 \mathrm{~N} \mathrm{HCl}$, washed with MilliQ water and separated from the suspension by centrifugation (Centurion Sci., 2040) at 3000 rpm for 5 min. Silver co-doping was accomplished by dissolving the desired amount of $\mathrm{AgNO}_{3}$ in solution $\mathrm{C}$ (Figure 1). However, $\mathrm{HNO}_{3}$ was used instead of $\mathrm{HCl}$ in the neutralisation step to avoid the precipitation of silver chloride. The obtained nanomaterials were dried in oven at $100{ }^{\circ} \mathrm{C}$ for $12 \mathrm{~h}$ and then calcined at $400{ }^{\circ} \mathrm{C}$ for $4 \mathrm{~h}$. Nitrogen-doped and silver co-doped photocatalysts are expressed hereafter as TiN and TiNAg, respectively.

\subsection{Characterisation of photocatalysts}

The surface area and pore structure of photocatalysts were examined by means of nitrogen $\left(\mathrm{N}_{2}\right)$ adsorption-desorption analyses using the BET and BJH methods. Nitrogen physical adsorption was performed using an automated surface area analyser (Micromeritics Gemini 2360, USA). Scanning electron microscope (SEM) micrographs were obtained by a FEI XL30 ESEM operating at $25 \mathrm{kV}$. High magnification images were obtained from a Philips CM200 (Netherland) transmission electron microscope (TEM) operating at $200 \mathrm{kV}$. XRD powder diffraction patterns were generated on a MDI Jade 5.0 (MaterialsData Inc., USA) X-ray diffractometer with $\mathrm{Cu} \mathrm{K \alpha}$ radiation source. The data were measured within the scattering 
angle $2 \theta$ range of $5^{\circ}-85^{\circ}$. Nitrogen and silver content and chemical states were measured using a Multilab2000 (VG, UK) X-ray photoelectron spectra (XPS) instrument with a nonmonochromatic $\mathrm{Mg} \mathrm{K \alpha}$ radiation at a residual gas pressure of below $10^{-9} \mathrm{~Pa}$. Diffuse reflectance spectra of powders were measured on a UV-vis scanning spectrophotometer (Cary 500 Scan, Varian, USA) by placing a thin film in the sample holder, which was inserted in the integrated sphere for reflectance measurements between $300 \mathrm{~nm}$ and $700 \mathrm{~nm}$.

\subsection{Photocatalytic activity}

The photocatalytic activity of nanopowders was studied by decomposing CV under simulated solar light. Batch experiments were carried out in glass beakers containing $200 \mathrm{~mL}$ of 10 mg/L CV solution $(\mathrm{pH}=6.2)$. After the addition of the desired amount of photocatalyst $(1$ $\mathrm{g} / \mathrm{L}$ ), the suspension was mixed with a magnetic stirrer at $360 \mathrm{rpm}$ for $30 \mathrm{~min}$ (dark adsorption). After reaching the adsorption equilibrium, photocatalysis took place in a Solar simulator (SolSim v1.2, Luzchem Research Inc., Canada) equipped with a $300 \mathrm{~W}$ Xenon lamp, a temperature controller, a magnetic stirrer and an air sparger to provide dissolved oxygen. Photocatalysis was carried out at 50,000 lx of simulated solar light for $6 \mathrm{~h}$ at a stable temperature of $26{ }^{\circ} \mathrm{C}$. Slurry samples were collected at fixed time intervals, filtered through $0.45 \mu \mathrm{m}$ Teflon syringe filters (Whatman, UNIFLO) and analysed using a Shimadzu UV-Vis 1700 spectrophotometer and a Multi N/C 3100 (Analytik Jena) dissolved organic carbon (DOC) analyser. The decrease in CV concentration was assessed by the decrease in the absorbance band at $590 \mathrm{~nm}$ over time.

Standard CV solutions were prepared and their absorbance was measured to draw a mathematical relationship between the decrease in absorbance and CV concentration. The linear relationship generated had the following formula: 
Abs $\left(\mathrm{cm}^{-1}\right)=0.018+0.166^{*}[C V]$

$R^{2}=0.997$

where $A b s$ is the absorbance at $\lambda=590 \mathrm{~nm}$ and $[C V]$ is the concentration of dye in $\mathrm{mg} / \mathrm{L}$.

\section{Results and discussion}

Morphology and porosity

Figure 2 shows SEM images of TiN and TiNAg powders. A mixed morphology of isotropic microspheres and aggregated nanoparticles is observed. The typical grain morphology of TiN and TiNAg is relatively similar with the majority of spheres in the size range of 1 to $2 \mu \mathrm{m}$. In TiNAg samples, silver could be detected by Ag flaring, revealing the scattered distribution of Ag on the $\mathrm{TiO}_{2}$ surface.

High magnification TEM images (Figure 3) revealed that the microspheres were composed of a large number of nanoparticles aggregated in a spherical form. Both photocatalysts showed a disordered mesostructure with a wide pore size distribution. Mesopores (2-50 nm) were formed among large nanoparticles (20-70 nm in size) in TiNAg, and in between smaller nanoparticles (5-40 $\mathrm{nm}$ in size) in TiN.

XRD analysis of diffraction patterns indicated that both TiN and TiNAg have the anatase crystal structure (Figure 4). Peaks at $2 \theta$ diffraction angles equal to $25.2^{\circ}, 38^{\circ}, 48.2^{\circ}, 55^{\circ}$ and $62.5^{\circ}$ were detected, which are attributed to different diffraction planes of anatase $\mathrm{TiO}_{2}$. Silver diffraction peaks were absent in the XRD patterns due to the low Ag concentration and scattered distribution on the surface of $\mathrm{TiO}_{2}$.

Important physical parameters of the photocatalysts are summarised in Table 1 . The asprepared powders (before calcination at $400{ }^{\circ} \mathrm{C}$ for $4 \mathrm{~h}$ ) showed a large surface area, up to 
$383.4 \mathrm{~m}^{2} / \mathrm{g}$ and $399.38 \mathrm{~m}^{2} / \mathrm{g}$ for TiN and TiNAg, respectively, but were reduced significantly by the calcination process. BET surface areas of calcined samples were comparable being $52.47 \mathrm{~m}^{2} / \mathrm{g}$ and $52.91 \mathrm{~m}^{2} / \mathrm{g}$ for TiN and TiNAg, respectively. Mean mesopore diameters (BJH desorption data) of TiN and TiNAg were $4.63 \mathrm{~nm}$ and $6.08 \mathrm{~nm}$, respectively. Nitrogen adsorption/desorption isotherms are shown in Figure 5. The adsorption isotherms have hysteresis loops that started at low $\mathrm{N}_{2}$ relative pressure owing to mesoporous characteristics. The isotherm curves were of type IV with H3 hysteresis loop that is usually observed with aggregates of plate-like particles leading to slit-shaped pores [26].

\subsection{DRS analysis}

Figure 6 shows the DRS spectra of the prepared samples. The absorbance properties of TiN and TiNAg were significantly different to those of undoped $\mathrm{TiO}_{2}$. The absorbance spectrum of the $\mathrm{N}$-doped sample calcined at $400{ }^{\circ} \mathrm{C}$ showed absorption at longer wavelengths than that of P25 [27]. Figure 6 also revealed an important band gap narrowing of the TiN photocatalyst compared to P25. The combination of $\mathrm{N}$ and Ag further shifted the absorbance to longer wavelengths but reduced the absorbance at all wavelengths. While TiN displayed the typical shoulder at $\sim 450 \mathrm{~nm}$ associated with localised electronic states near the conduction band [28], TiNAg exhibited a continuous shift to $550 \mathrm{~nm}$.

\subsection{XPS analysis}

Figure 7 shows the XPS spectra in the N 1s and Ag 3d regions for TiN and TiNAg. For TiN, $\mathrm{O}$ 1s peaks were recorded at $530.1 \mathrm{eV}$ and $531.4 \mathrm{eV}$ and were ascribed to O-Ti-O oxygen coordination and chemisorbed oxygen or hydroxyl oxygen atoms, respectively [6]. The $\mathrm{N} 1 \mathrm{~s}$ peak at $400.1 \mathrm{eV}$ indicated that $\mathrm{N}$ exists in the form of adsorbed $\mathrm{NO}[1,5,27,28]$. The assignment of the $\mathrm{N}$ 1s peak has been a source of debate for researchers in the past few years. 
Peak assignment in nitrogen doped $\mathrm{TiO}_{2}$ has been reviewed and discussed in detail by Emeline and co-workers [28]. Sato et al. [1] reported the synthesis of $\mathrm{N}$-doped $\mathrm{TiO}_{2}$ by a wet method and their XPS results showed an $\mathrm{N}$ 1s peak at $400 \mathrm{eV}$, which was assigned to adsorbed $\mathrm{NO}_{\mathrm{x}}$ species. In our case, nitrogen incorporation appeared in the form of Ti-O-N, based on the binding energies of $\mathrm{O}(\approx 530 \mathrm{eV}$ and $531.4 \mathrm{eV})$ and $\mathrm{N}(\approx 400 \mathrm{eV})$. Before the calcination of TiN powder at $400{ }^{\circ} \mathrm{C}$, two distinct $\mathrm{N}$ 1s peaks were detected at approx. 400 $\mathrm{eV}$ and $405 \mathrm{eV}$, at 5 at.\% $\mathrm{N}$ content and the samples had a strong yellow colour. After calcination, the peak at $405 \mathrm{eV}$ disappeared from the spectrum, the nitrogen content was reduced to 1.38 at.\% and the colour became pale yellow (Table 2). These changes indicated that most of the adsorbed nitrogen species (mainly $\mathrm{NO}_{\mathrm{x}}$ ) were desorbed during annealing.

In the TiNAg sample, similar nitrogen $(\approx 399 \mathrm{eV})$ and oxygen $(\approx 530 \mathrm{eV})$ peaks were recorded (O-Ti-O, N-O-Ti). The percentage of $\mathrm{N}$ was higher in co-doped samples, while the Ag content ranged from 0.15 at.\% to 0.2 at.\% (Table 2). Gu et al. [18] also found that the concentration of $\mathrm{N}$ in $\mathrm{N}$-doped samples was lower than in $\mathrm{N}-\mathrm{V}$ co-doped powders, ascribing this to the decrease in the energy barrier for nitridation caused by $\mathrm{V}$ atoms. Ag $3 \mathrm{~d}$ peaks indicated that silver exists in $\mathrm{Ag}^{3+}$ or $\mathrm{AgO}$ forms [22, 29]. Since the ionic radius of $\mathrm{Ag}^{+}(129$ $\mathrm{pm})$ is significantly bigger than that of $\mathrm{Ti}^{4+}(74.5 \mathrm{pm})$, physical substitution is unlikely to occur. However, $\mathrm{Ag}^{3+}(89 \mathrm{pm})$ and $\mathrm{Ti}^{3+}(81 \mathrm{pm})$ have relatively similar ionic radii, which increased the chance of substitution between the two. This was further substantiated by the binding energies of Ag $3 \mathrm{~d} 5$ (365.8 eV) and Ti 2p3 (457.8 eV). The lattice distortion caused by the incorporation of $\mathrm{Ag}$ in $\mathrm{TiO}_{2}$ induced a decrease in the bond strength of O-Ti-O bonds [30]. In turn, this reduced the energy barrier and allowed for more $\mathrm{N}$ atoms to bind to $\mathrm{O}$ in the form of NO species.

\subsection{Photocatalytic activity}


The photocatalytic degradation of Crystal Violet (CV) over time is shown in Figure 8. The decrease of absorbance at $\lambda=590 \mathrm{~nm}$ due to photolysis (in the absence of photocatalyst) was insignificant, about $10-15 \%$ in $6 \mathrm{~h}$ of simulated solar light irradiation. However, this discolouration (photo-bleaching) was not coupled with a decrease in dissolved organic carbon (DOC), which indicated the degradation of CV into several N-de-methylated reaction intermediates (organic by-products) [31].

After the addition of photocatalyst, the suspension was left in dark for $30 \mathrm{~min}$ to reach adsorption equilibrium. Both photocatalysts showed low adsorption affinity to $\mathrm{CV}$, decreasing the concentration of dye in solution by approx. $5 \%$. The discolouration of CV solution was almost complete after $6 \mathrm{~h}$ of irradiation. Little difference was observed between TiN and TiNAg for the discolouration of CV under the experimental conditions described above. The limited increase in photocatalytic activity for the co-doped photocatalysts may be due to the relatively low concentration and scattered distribution of Ag.

It should be noted that the decrease in colour only indicated the photo-bleaching of dyes but not their complete mineralisation in photocatalytic reactions. However, photocatalytic mineralisation can be verified by measuring the decrease of DOC during photocatalysis. DOC results shown in Figure 8 indicated that the photodegradation of organic by-products was not complete after 6 h of photocatalysis. DOC was decreased from $6.3 \mathrm{mg} / \mathrm{L}$ to $2.8 \mathrm{mg} / \mathrm{L}$ and $2.5 \mathrm{mg} / \mathrm{L}$ for TiN and TiNAg, respectively. The results showed that TiN and TiNAg had comparable performances in the photo-mineralisation of $\mathrm{CV}$ and its $\mathrm{N}$-de-methylated byproducts. Furthermore, data on absorbance at $\lambda=540 \mathrm{~nm}$ (pararosaniline detection wavelength) indicated no residual colour at the end of the experiment (Figure 8). The photodegradation of pararosaniline was investigated by Martins et al. [32]. The analysis of formed by-products by the degradation process showed that formic acid is the main organic compound present in solution in addition to carboxylic acid, aldehydes and ketones. In our 
case, the residual DOC revealed the persistence of organic by-products in solution which needed more time for complete mineralisation. These by-products would be a mixture of formic acid, carboxylic acids, aldehyde and ketones. Their total removal is possible by prolonging the photodegradation reaction time.

\section{Conclusions}

The synthesis of $\mathrm{N}$ doped and N/Ag co-doped photocatalysts was done using a simple sol-gel method at room temperature. TiN and TiNAg showed mixed morphology of aggregated nanoparticles and spherical microspheres. The obtained amorphous powders were crystallised to anatase forms after annealing at $400{ }^{\circ} \mathrm{C}$ for $4 \mathrm{~h}$. Both materials revealed $\mathrm{N}$ 1s peak around $400 \mathrm{eV}$ which can be assigned to NO adsorbed species. The Ag doping state was identified in the form of $\mathrm{Ag}^{3+}$ or AgO. Both photocatalysts were able to decolourise and reduce the DOC of CV solutions under simulated solar light irradiation.

\section{Acknowledgment}

This research was funded by ARC-LP (LP0991544), a UTS internal grant and Australian Postgraduate Award scholarship. This work was also supported by Priority Research Centers Program through the National Research Foundation of Korea (NRF) funded by the Ministry of Education, Science and Technology (2011-0030747).

\section{References}

[1] S. Sato, Chem. Phys. Lett. 123 (1986) 126-128.

[2] R. Asahi, T. Morikawa, T. Ohwaki, K. Aoki, Y. Taga, Science 293 (2001) 269-271.

[3] E. Stathatos, T. Petrova, P. Lianos, Langmuir 17 (2001) 5025-5030. 
[4] C. Burda, Y. Lou, X. Chen, A.C.S. Samia, J. Stout, J.L. Gole, Nano Lett. 3 (2003) 1049-1051.

[5] M. Sathish, B. Viswanathan, R.P. Viswanath, C.S. Gopinath, Chem. Mater. 17 (2005) 6349-6353.

[6] T.C. Jagadale, S.P. Takale, R.S. Sonawane, H.M. Joshi, S.I. Patil, B.B. Kale, S.B. Ogale, J. Phys. Chem. C 112 (2008) 14595-14602.

[7] K.A. Michalow, D. Logvinovich, A. Weidenkaff, M. Amberg, G. Fortunato, A. Heel, T. Graule, M. Rekas, Catal. Today 144 (2009) 7-12.

[8] M. Xing, J. Zhang, F. Chen, Appl. Catal. B 89 (2009) 563-569.

[9] D. Chatterjee, S. Dasgupta, J. Photoch. Photobio. C 6 (2005) 186-205.

[10] A. Zaleska, Recent Pat. Eng. 2 (2008) 157-164.

[11] S. Rehman, R. Ullah, A.M. Butt, N.D. Gohar, J. Hazard. Mater. 170 (2009) 560-569.

[12] S. Malato, P. Fernández-Ibáñez, M.I. Maldonado, J. Blanco, W. Gernjak, Catal. Today 147 (2009) 1-59.

[13] C.L. Bianchi, G. Cappelletti, S. Ardizzone, S. Gialanella, A. Naldoni, C. Oliva, C. Pirola, Catal. Today 144 (2009) 31-36.

[14] H. Ichinose, M. Taira, S. Furuta, H. Katsuki, J. Am. Ceram. Soc. 86 (2003) 16051608.

[15] Y. Gao, Y. Masuda, Z. Peng, T. Yonezawa, K. Koumoto, J. Mater. Chem. 13 (2003) 608-613.

[16] Y. Gao, Y. Masuda, W.-S. Seo, H. Ohta, K. Koumoto, Ceram. Int. 30 (2004) 13651368.

[17] B. Ohtani, Y. Azuma, D. Li, T. Ihara, R. Abe, Trans. Mater. Res. Soc. Jpn. 32 (2007) 401-404.

[18] D.-E. Gu, B.-C. Yang, Y.-D. Hu, Catal. Commun. 9 (2008) 1472-1476. 
[19] A. Kubacka, B. Bachiller-Baeza, G. Colón, M. Fernández-García, Appl. Catal. B: 93 (2010) 274-281.

[20] I. El Saliby, L. Erdei, H.K. Shon, J.-H. Kim, J. Ind. Eng. Chem. 17 (2011) 358-363.

[21] S. Senthilkumaar, K. Porkodi, J. Colloid Interf. Sci. 288 (2005) 184-189.

[22] H.W. Chen, Y. Ku, Y.L. Kuo, Chem. Eng. Technol. 30 (2007) 1242-1247.

[23] L. Liu, Z. Liu, H. Bai, D.D. Sun, Water Res. 46 (2012) 1101-1112.

[24] H. Bai, Z. Liu, D.D. Sun, Chem. Asian J. 7 (2012) 1772-1780.

[25] J.H. Pan, X. Zhang, A.J. Du, D.D. Sun, J.O. Leckie, J. Am. Chem. Soc. 130 (2008) 11256-11257.

[26] K.S.W. Sing, D.H. Everett, R.A.W. Haul, L. Moscou, R.A. Pierotti, J. Rouquerol, T. Siemieniewska, Pure. Appl. Chem. 57 (1985) 603-619.

[27] S. Sato, R. Nakamura, S. Abe, Appl. Catal. A 284 (2005) 131-137.

[28] A.V. Emeline, V.N. Kuznetsov, V.K. Rybchuk, N. Serpone, Int. J. Photoenergy Volume 2008, Article ID 258394, 19 pages.

[29] D. Lützenkirchen-Hecht, H.-H. Strehblow, Surf. Interface. Anal. 41 (2009) 820-829.

[30] C.Q. Sun, Prog. Solid. State. Ch. 35 (2007) 1-159.

[31] C.-C. Chen, H.-J. Fan, C.-Y. Jang, J.-L. Jan, H.-D. Lin, C.-S. Lu, J Photochem. Photobio. A 184 (2006) 147-154.

[32] A.d.O. Martins, V.M. Canalli, C.M.N. Azevedo, M. Pires, Dyes Pigments 68 (2006) 227-234. 


\section{Tables}

Table 1

Structural parameters of nitrogen doped and silver co-doped photocatalysts

\begin{tabular}{|l|l|l|l|}
\hline Photocatalyst & $S_{B E T}^{a}\left(\mathrm{~m}^{2} / \mathrm{g}\right)$ & $V_{p}^{b}\left(\mathrm{~cm}^{3} \mathrm{~g}^{-1}\right)$ & $D_{p}^{c}(\AA)$ \\
\hline TiN & 52.47 & 0.23 & 46.30 \\
\hline TiNAg & 52.91 & 0.31 & 60.87 \\
\hline
\end{tabular}

${ }^{\mathrm{a}}$ BET surface area

${ }^{\mathrm{b}}$ Total mesopore volume

${ }^{\mathrm{c}}$ Mean mesopore diameter as estimated from nitrogen desorption isotherms using the BarrettJoyner-Halenda (BJH) model 
Table 2

Chemical composition of photocatalysts obtained from XPS elemental analysis

\begin{tabular}{|l|l|l|l|l|}
\hline Sample & Ti (at.\%) & O (at.\%) & N (at.\%) & Ag (at.\%) \\
\hline TiN & 36.69 & 55.24 & 1.38 & - \\
\hline TiNAg & 38.78 & 56.37 & 1.46 & $0.15-0.2$ \\
\hline
\end{tabular}




\section{List of Figures}

Figure 1. Scheme describing different steps in TiN and TiNAg synthesis.

Figure 2. SEM micrographs of prepared photocatalysts.

Figure 3. TEM images of TiN and TiNAg.

Figure 4. XRD diffraction patterns of TiN and TiNAg.

Figure 5. Nitrogen adsorption/desorption isotherms of TiN and TiNAg.

Figure 6. DRS spectra of TiN and TiNAg.

Figure 7. XPS spectra for the N 1s region of TiN and TiNAg and the Ag 3d region of TiNAg.

Figure 8. Photocatalytic discolouration and DOC removal of CV solution using TiN and TiNAg under simulated solar light $\left([\mathrm{CV}]=10 \mathrm{mg} / \mathrm{L}\right.$, Catalyst loading $=1 \mathrm{~g} / \mathrm{L}, \mathrm{T}=26^{\circ} \mathrm{C}$, air sparging $=0.6 \mathrm{~L} / \mathrm{min}, \mathrm{pH}=6.2$, sampling done every $30 \mathrm{~min}$ ). 


\section{Figure 1}

A

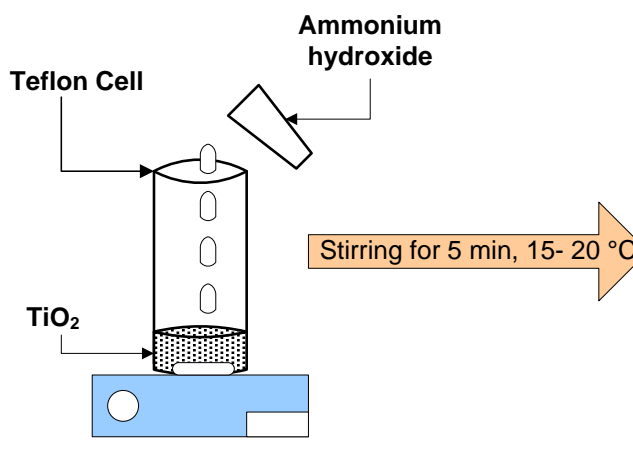

Magnetic Stirrer
B

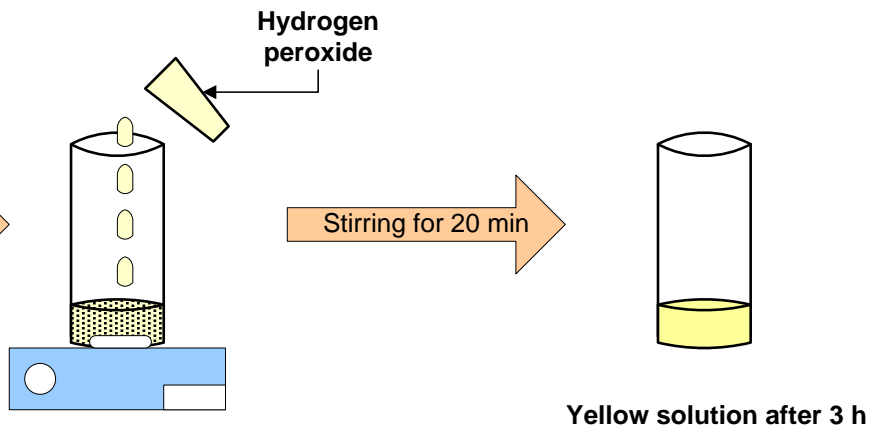

C

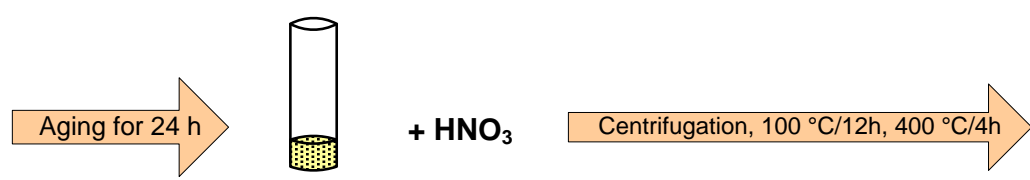

N/Ag-doped $\mathrm{TiO}_{2}$

Solution C

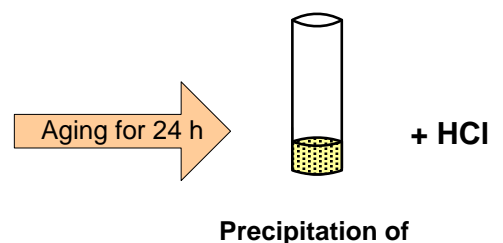

nanomaterials

$\mathrm{TiO}_{2}$ 
Figure 2
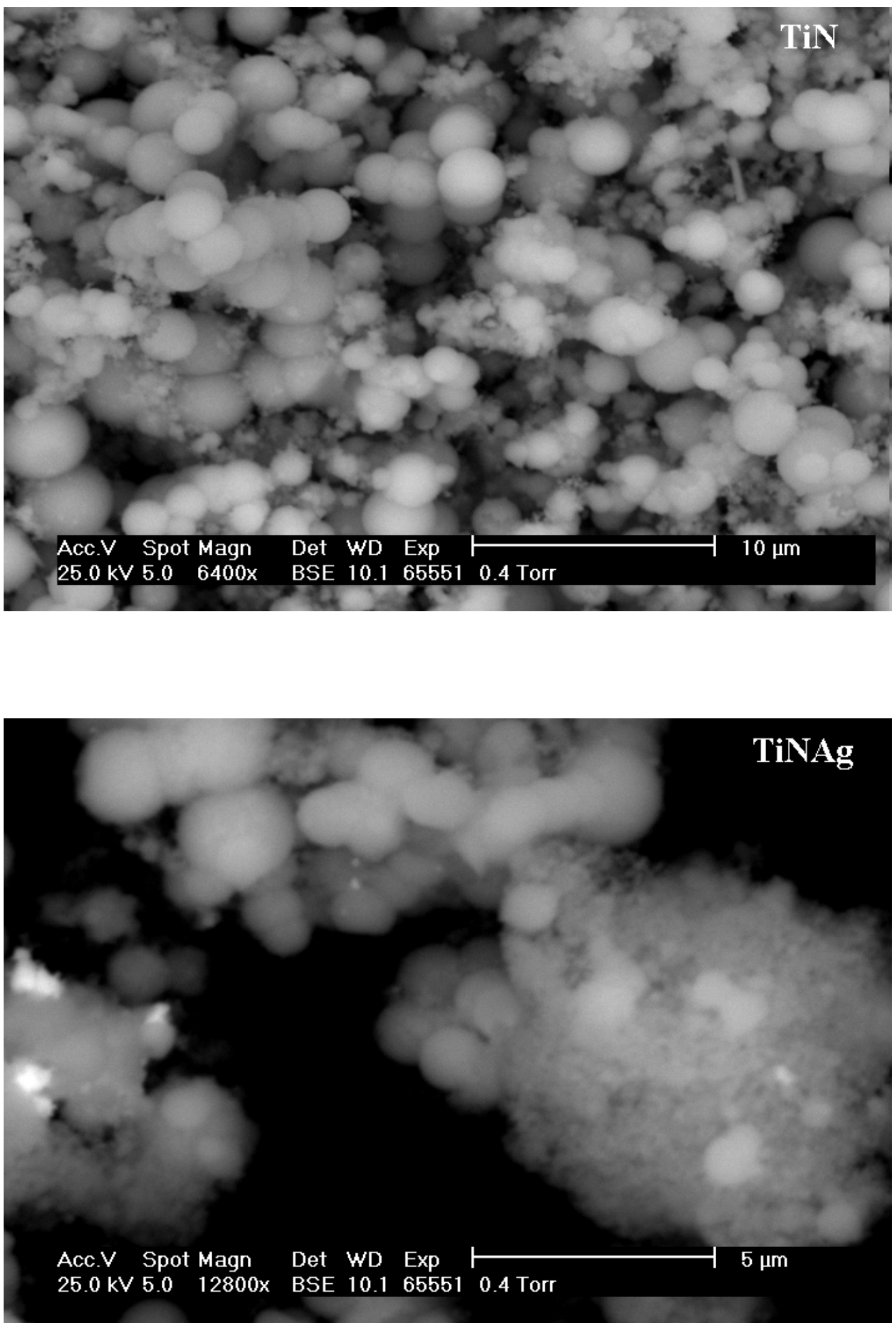


\section{TiNAg}

Acc.V Spot Magn

Det WD Exp

$25.0 \mathrm{kV} 5.0 \quad 25600 \mathrm{x} \quad$ BSE $10.165551 \quad 0.4$ Torr 
Figure 3
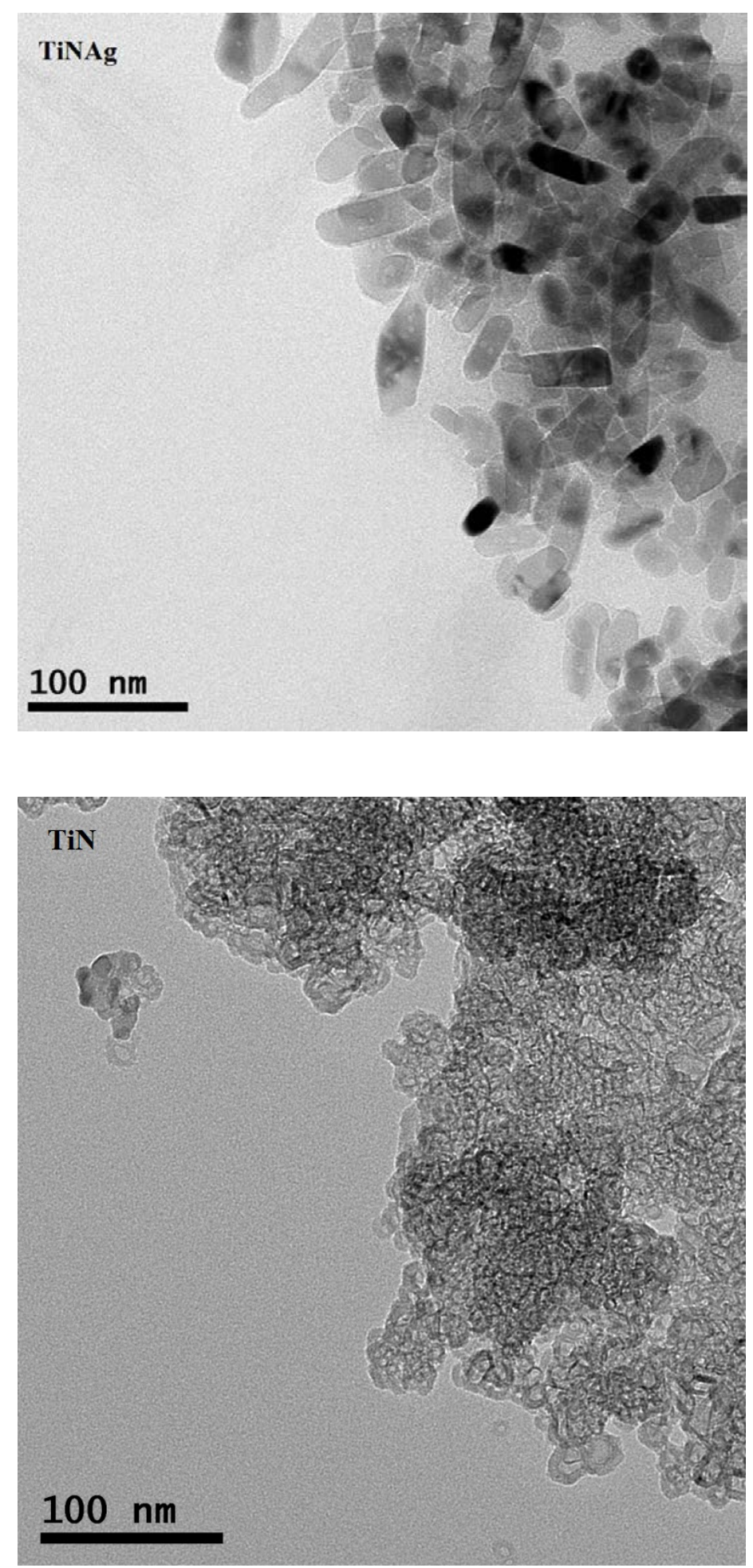
Figure 4

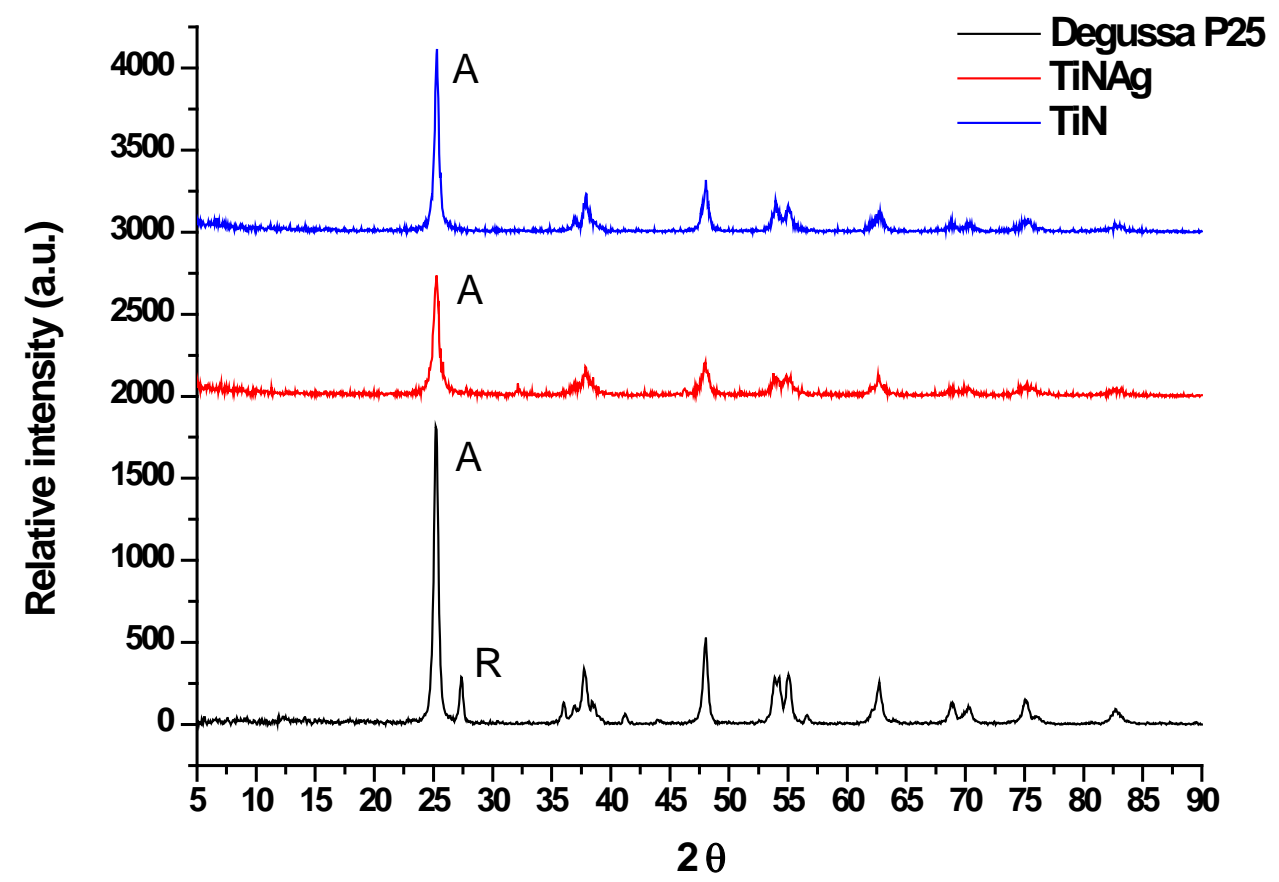


Figure 5
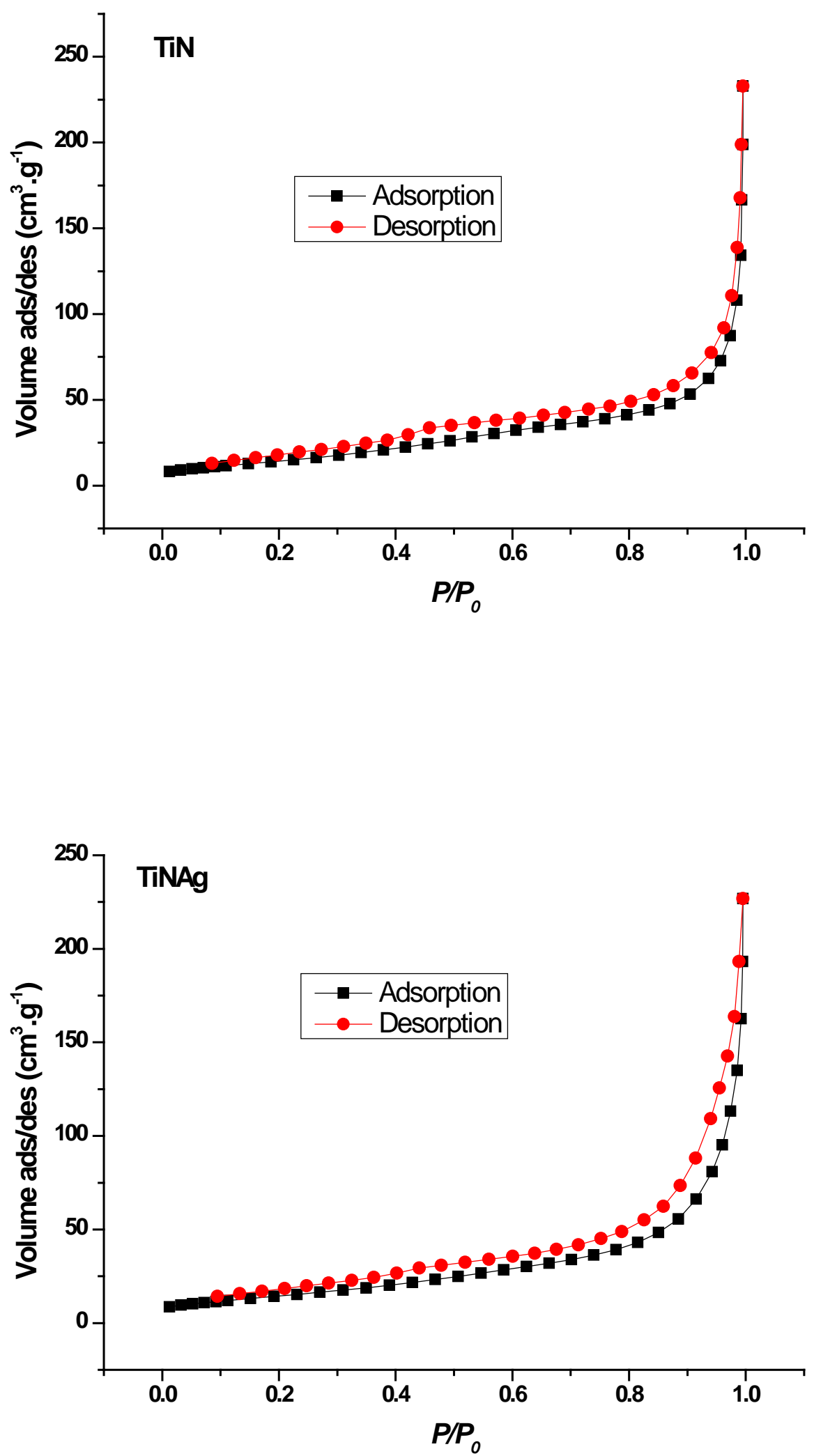
Figure 6

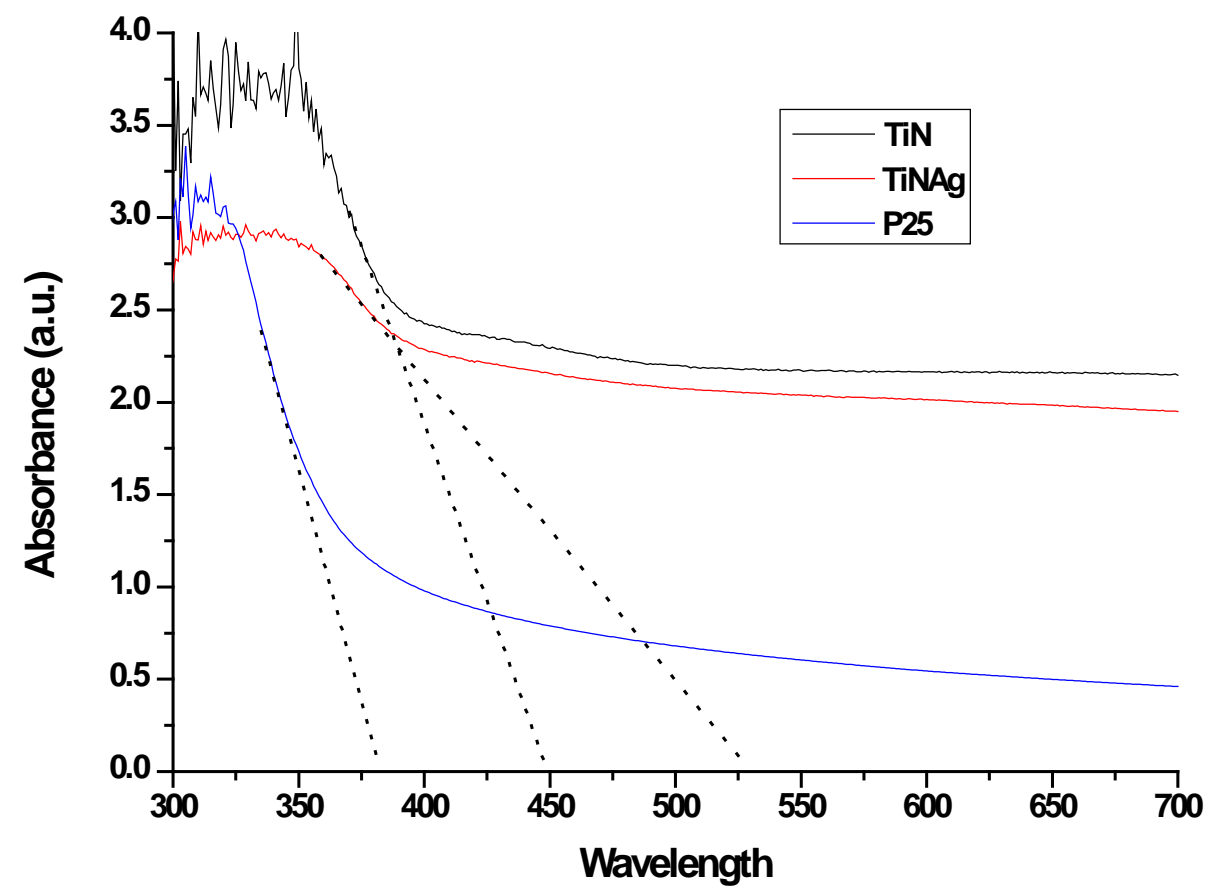


Figure 7
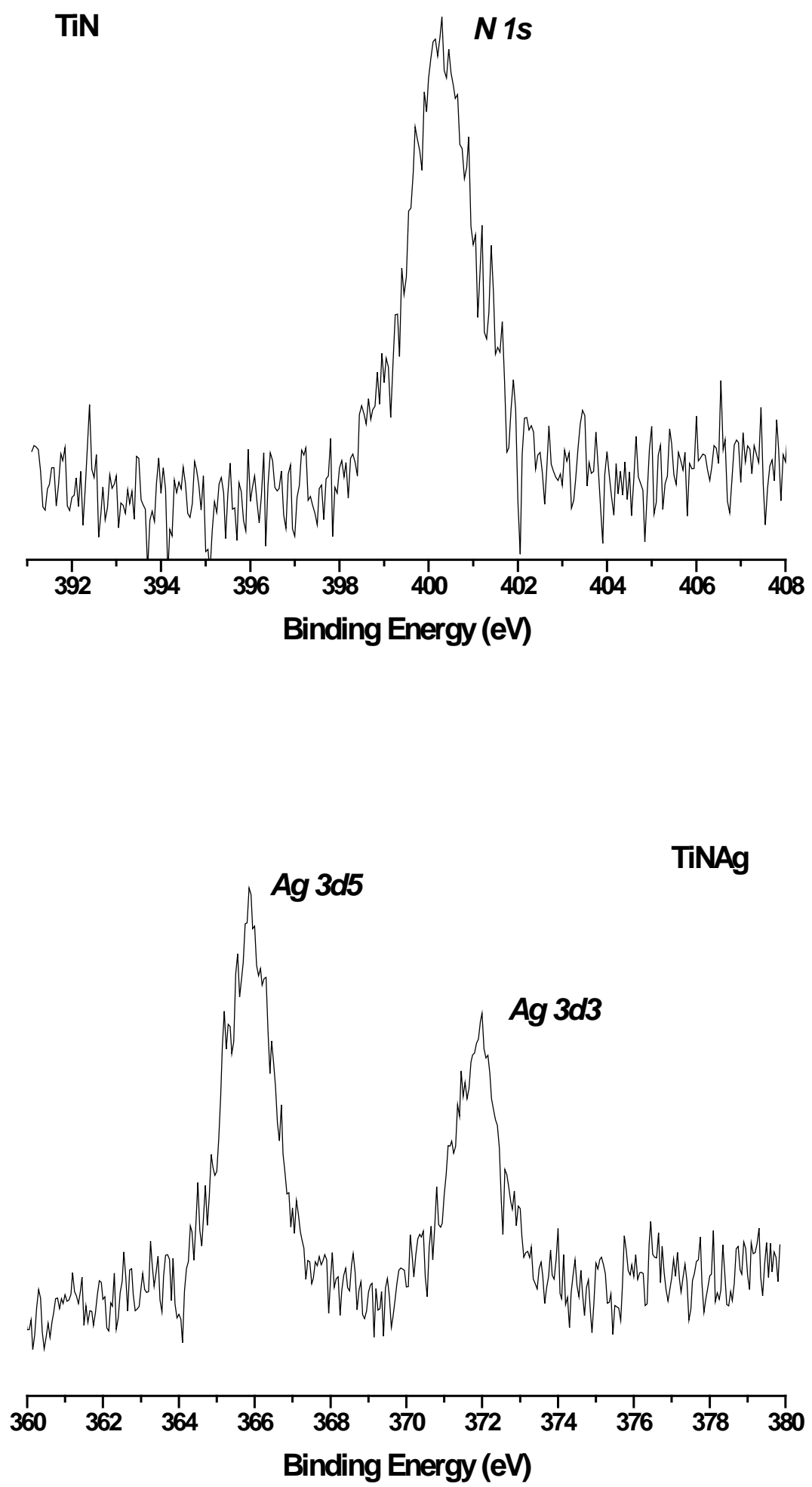


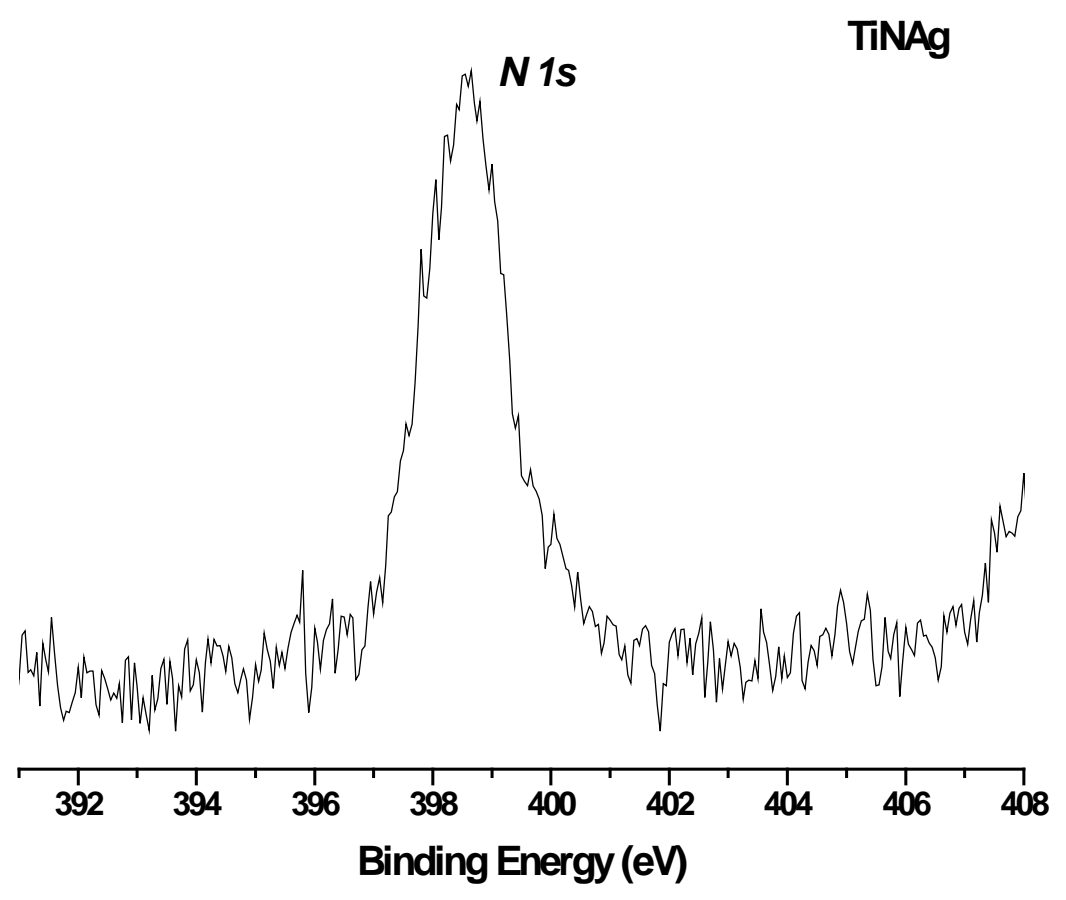


Figure 8
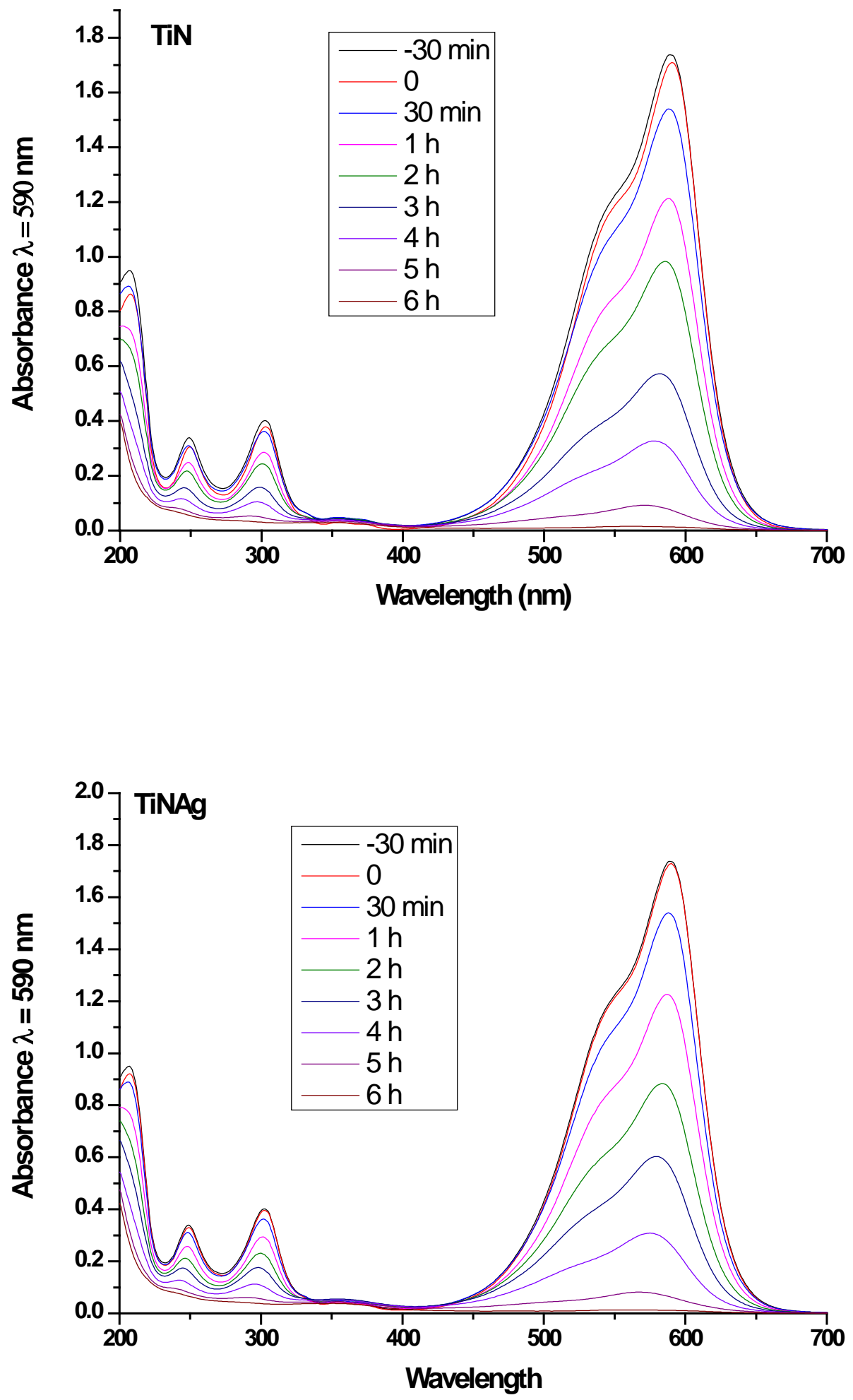

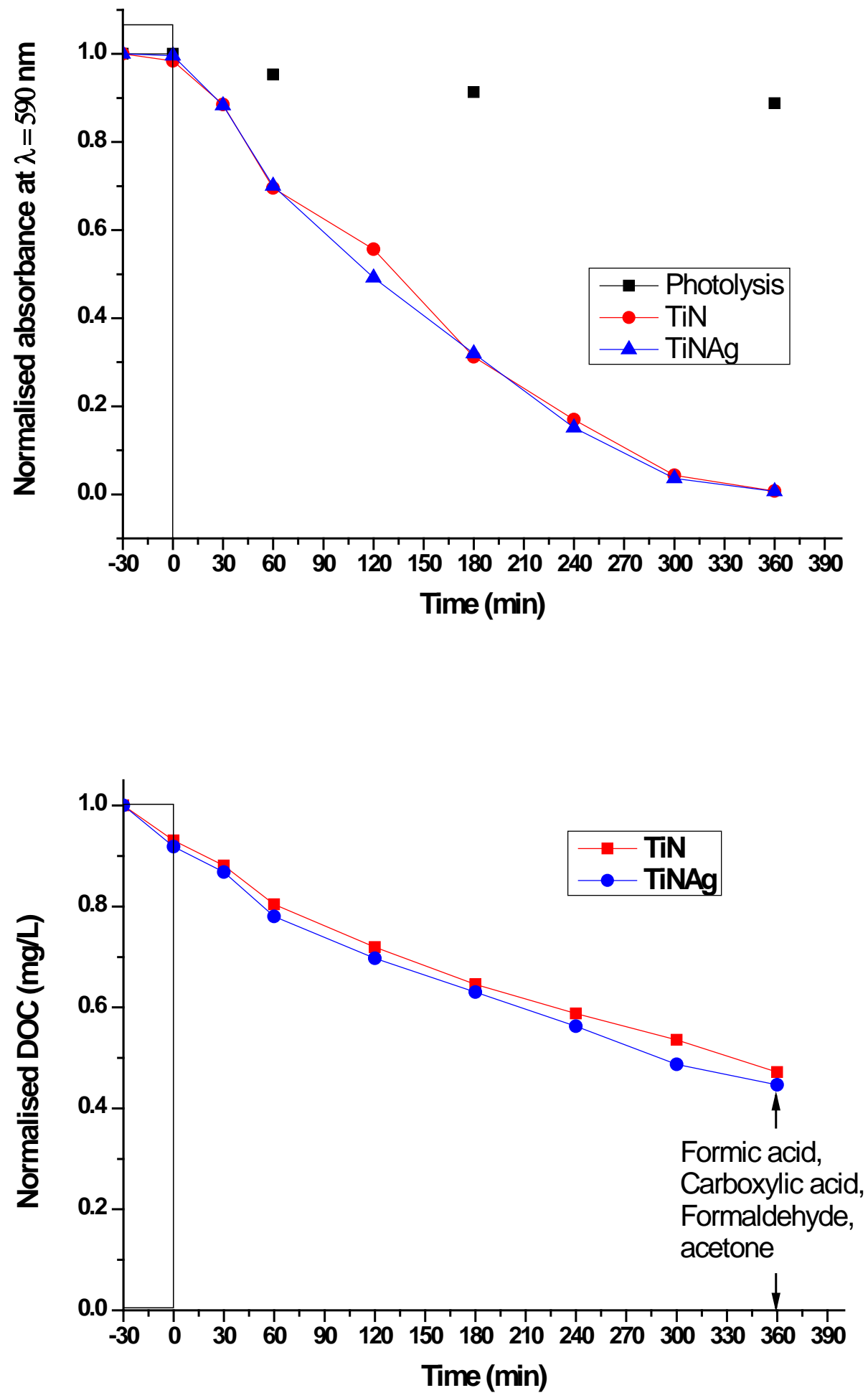